\title{
Defects-per-unit control chart for assembled products based on defect prediction models
}

\author{
Elisa Verna ${ }^{1} \cdot$ Gianfranco Genta $^{1} \cdot$ Maurizio Galetto $^{1} \cdot$ Fiorenzo Franceschini $^{1}[0$
}

Received: 15 July 2021 / Accepted: 28 September 2021 / Published online: 31 October 2021

(c) The Author(s) 2021, corrected publication 2022

\begin{abstract}
Typically, monitoring quality characteristics of very personalized products is a difficult task due to the lack of experimental data. This is the typical case of processes where the production volume continues to shrink due to the growing complexity and customization of products, thus requiring low-volume productions. This paper presents a novel approach to statistically monitor defects-per-unit (DPU) of assembled products based on the use of defect prediction models. The innovative aspect of such DPU-chart is that, unlike conventional SPC charts requiring preliminary experimental data to estimate the control limits (phase I), it is constructed using a predictive model based on a priori knowledge of DPU. This defect prediction model is based on the structural complexity of the assembled product. By avoiding phase I, the novel approach may be of interest to researchers and practitioners to speed up the chart's construction phase, especially in low-volume productions. The description of the method is supported by a real industrial case study in the electromechanical field.
\end{abstract}

Keywords Quality control · Defect prediction · Control charts · Assembly · Low-volume production

\section{Introduction}

Nowadays, control charts have become an essential part of the quality control activities of most organizations to detect the presence of special causes of variation in a variety of manufacturing processes [1-4].

Traditional control charts require a preliminary set of experimental data related to the process to be constructed (phase I) [5]. However, there can be situations in which collecting this data set can be time-consuming, costly, and difficult to obtain. This is the typical case of low-volume productions, for which collecting a reasonable number of samples to set valid control limits may unacceptably delay monitoring [6-8].

The purpose of this paper is to propose a novel approach to statistically control the process of assembled products through the use of a control chart for nonconformities per unit (DPU-chart) based on defect prediction models.

Fiorenzo Franceschini

fiorenzo.franceschini@polito.it

1 Department of Management and Production Engineering, Politecnico Di Torino, Corso Duca degli Abruzzi 24, 10129 Torino, Italy
In detail, if a defect prediction model based on a priori knowledge of the defectiveness occurring in the product is available, it can be used to construct a DPU-chart by avoiding the traditional implementation of phase I.

In this study, assembly processes are addressed in detail. In particular, a defect prediction model developed in a recent study by the authors [9] is used to set up a control chart to monitor DPU detected in each workstation of a manufacturing process. This model relies on the relationship between DPU and product structural complexity.

The DPU-chart, despite the conceptual similarity with traditional $u$-chart, totally differs in its design. This control chart does not require a process analysis and a preliminary experimental data collection (phase I). As a result, the methodology proposed could be of interest to researchers and practitioners that need to speed up the phase of construction of the chart. In particular, as mentioned, the proposed DPUchart could be very attractive for low-volume productions.

The proposed method is applied to a real-world case study related to the production of wrapping machines assembly for the packaging of palletized load, whose total number of machines produced in a year generally reaches only a few dozen units.

The remainder of the paper is organized into five sections. "Sect. 2" reviews the prediction model for assembly 
defects. In "Sect. 3," the DPU-chart is presented. "Sect. 4" presents a case study concerning the practical application of the proposed control chart in the low-volume production of wrapping machines. "Sect. 5" provides some guidelines for the practical application of the DPU-chart. "Sect. 6" summarizes the original contributions of this research, focusing on its implications, limitations, and possible future developments.

\section{Conceptual background: defect prediction model for assembly processes}

A large number of studies in the literature use assembly complexity to predict product defects $[8,10-20]$. These models were developed for predictive and quality improvement purposes in several industrial fields, ranging from the electromechanical to the automotive sector. Most of them refer to mass productions, involving hundreds or thousands of pieces produced per month [10,11,13-17, 19]. Recently, the authors focused on identifying appropriate defect prediction models in assembly processes [9, 21-24] according to the product structural complexity paradigm proposed by Alkan [25] and Sinha [26]. The same model was also recently adopted to help inspection designers in the inspection process planning from the early design phases [9].
In detail, the product assembly process is decomposed into a series $(m)$ of process steps, also called workstations, following specific operation standards. Each $i$-th workstation $(i=1, \ldots, m)$ is made up of several elementary operations, defined as the minimum components of a specific task, as schematized in Fig. 1.

It is assumed that errors made by operators in performing a certain elementary operation in a workstation may introduce at most one defect in the product that can be interpreted as a unique "macro-defect." Accordingly, the totality of the possible defects within a certain workstation is at most equal to the total number of elementary operations in the same workstation. In practical applications, such assumption is reasonable when, for each $i$-th workstation, a refined segmentation of elementary operation is performed. Each sub-assembly coming from a workstation, i.e., a workstation-output, can be examined by inspectors using quality control activities appropriate according to the specific type of defects, e.g., dimensional verifications, visual checks, or mechanical tests.

To clarify these last concepts, a pedagogical example is proposed. Consider a simple assembly process composed by a single workstation, in which a bolt (with a nut) is manually tightened with a wrench. Table 1 shows the performed elementary operations with the defects that may be introduced. In this case, the number of elementary operations is
Fig. 1 Schematic of the assembly process of a product $[9,24]$

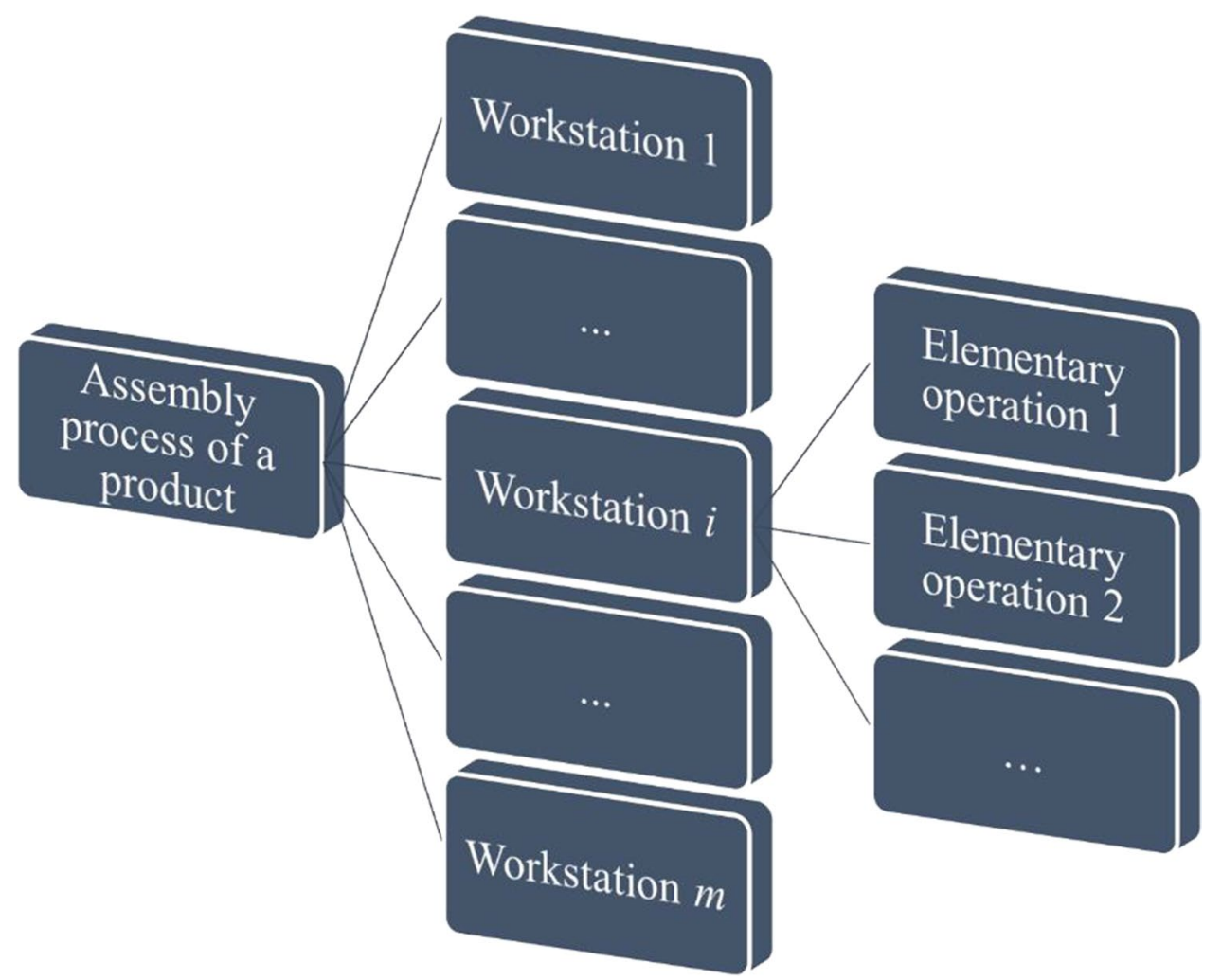


Table 1 Subdivision of a workstation, i.e., the manually tightening of a bolt with a wrench in an apparatus, into elementary operations with indication of possible defects

\begin{tabular}{|c|c|c|}
\hline $\begin{array}{l}\text { Elementary } \\
\text { operation no }\end{array}$ & Elementary operation description & Possible defect \\
\hline 1 & Reach for bolt & Bolt is confused with other fasteners \\
\hline 2 & Grasp at bolt with the left (or right) hand & Fall of the bolt \\
\hline 3 & Move the bolt to the apparatus & Bolt not moved to the exact location \\
\hline 4 & Position the bolt in the hole & Bolt positioned out of the hole \\
\hline 5 & Grasp the nut with the right (or left) hand & Fall of the nut \\
\hline 6 & Position the nut on the bolt thread & Nut wrongly positioned on the thread \\
\hline 7 & Grab the wrench with the right (or left) hand & Fall of the wrench \\
\hline 8 & Position the wrench on the nut & Wrench wrongly positioned on the nut \\
\hline 9 & Turn the wrench to tighten the nut & Damage to the nut \\
\hline
\end{tabular}

9 and, accordingly, the total number of possible defects that can occur in the workstation is at most 9 .

Verna et al. $[9,24]$ showed that the total number of defects detected in each $i$-th workstation divided by the number of produced units, i.e., the defects per unit related to the $i$-th workstation $\left(D P U_{i}\right)$, can be expressed as a function of product complexity, as follows:

$D P U_{i}=f\left(C_{i}\right)$

where $D P U_{i}$ is the defect per unit (DPU) in the $i$-th workstation and $C_{i}$ is the structural complexity associated to the $i$-th workstation, evaluated according to the approach proposed by Alkan [25] and Sinha [26], shown in Eq. (2).

$C_{i}=C_{1, i}+C_{2, i} \cdot C_{3, i}$

The three components of the structural complexity, $C_{1, i}$, $C_{2, i}$, and $C_{3, i}$, are described below.

$C_{1, i}$ is defined as the handling complexity of the $i$-th workstation and is the sum of complexities of individual product parts in each $i$-th workstation. It is calculated as shown in Eq. (3):

$C_{1, i}=\sum_{p=1}^{N_{i}} \gamma_{p i}$

where, for each $i$-th workstation $(i=1, \ldots, m), N_{i}$ is the total number of product parts and $\gamma_{p i}$ is the handling complexity of part $p$, which can be approximated by the standard handling time [25].

$C_{2, i}$ represents the complexity of connections related to the $i$-th workstation. It is the sum of the complexities of pairwise connections existing in the product structure assembled in the $i$-th workstation, as follows:

$C_{2, i}=\sum_{p=1}^{N_{i}-1} \sum_{r=p+1}^{N_{i}} \varphi_{p r i} \cdot A_{p r i}$ where $\varphi_{p r i}$ is the complexity in achieving a connection between parts $p$ and $r$ of the $i$-th workstation, and $A_{p r i}$ defines the binary adjacency matrix of the $i$-th workstation. Note that the connection between parts is considered only once. In detail, $\varphi_{p r i}$ can be approximated by the standard completion time of the connection between parts $p$ and $r$ in isolated conditions. Besides, $A_{p r i}$ represents the connectivity structure of the system, as indicated in Eq. (5):

$\mathrm{A}_{\mathrm{pri}}=\left\{\begin{array}{l}1 \text { if there is a connection between } p \text { and } r \text { in the } i-\text { th workstation } \\ 0 \quad \text { otherwise }\end{array}\right.$

Finally, $C_{3, i}$ is the topological complexity of the $i$-th workstation and represents the complexity related to the architectural pattern of the assembled product. It can be obtained from the matrix energy $E_{A i}$ of the adjacency matrix related to the $i$-th workstation, which is designated by the sum of the corresponding singular values $\delta_{q i}[26,27]$, as follows:

$C_{3, i}=\frac{E_{A i}}{N_{i}}=\frac{\sum_{q=1}^{N_{i}} \delta_{q i}}{N_{i}}$

where $E_{A i}$ stands for graph energy (or matrix energy) related to $i$-th workstation and $N_{i}$ stands for the number of parts in the $i$-th workstation (i.e., the number of nodes). As the adjacency matrix of each $i$-th workstation is a symmetric matrix of size $N_{i}$ with the diagonal elements being all zeros, the singular values corresponds to the absolute eigenvalues of the adjacency matrix [26, 28].

To clarify how the structural complexity associated to the $i$-th workstation can be obtained, a simple example is given. Consider an assembly process made up of a single workstation in which a simple product composed of $N=6$ parts $(w, j, k, x, y$, and $z)$ is assembled, as represented in Fig. 2. For the sake of simplicity, suppose that the 6 parts, as well as the connections between the parts, are identical. The standard handling time of each $p$-th part is $\gamma_{p}=10 \mathrm{~s}$ (with $p=1, \ldots, 6$ ), while the standard completion time of the connection between parts $p$ and $r$ is $\varphi_{p r}=20 \mathrm{~s}$ (with 


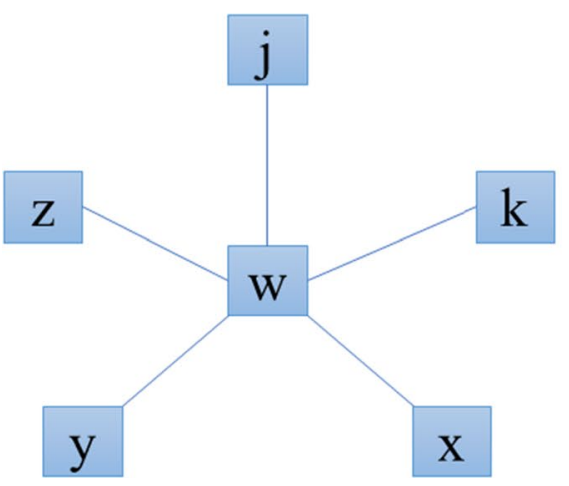

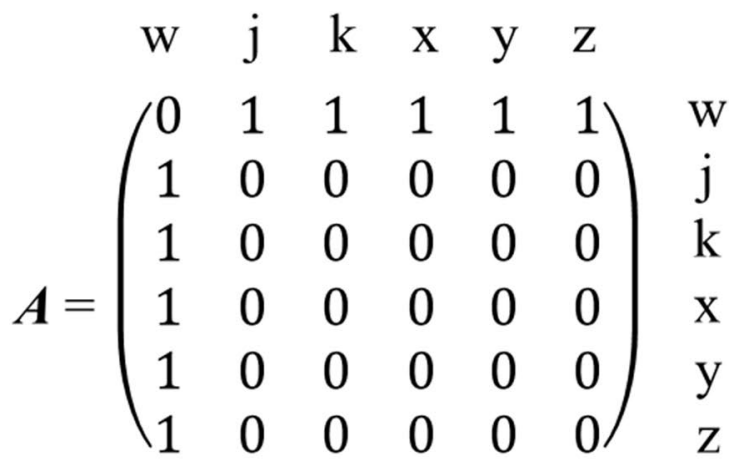

Fig. 2 Connectivity structure of a simple product composed of six parts and its associated adjacency matrix $\boldsymbol{A}$

$p=1, \ldots, 5$ and $r=p+1, \ldots, 6$ ). According to Eq. (3), the handling complexity is $C_{1}=\sum_{p=1}^{6} \gamma_{p}=60 \mathrm{~s}=1 \mathrm{~min}$. The complexity of connections is, by implementing Eq. (4), $C_{2}=\sum_{p=1}^{5} \sum_{r=p+1}^{6} \varphi_{p r} \cdot A_{p r}=100 \mathrm{~s}=1.67 \mathrm{~min}$, since there are 5 connections between the parts. From the adjacency matrix $\boldsymbol{A}$, shown in Fig. 2, the related graph energy is computed as the sum of its singular values that are the absolute eigenvalues of $\boldsymbol{A}$ in case of symmetric matrix. In detail, the eigenvalues of the adjacency matrix $\boldsymbol{A}$ are $-2.24,2.24$, and 0 with multiplicity 4 . Thus, being the singular values the absolute eigenvalues of $\boldsymbol{A}$, then $E_{A}=2.24 \cdot 2+0 \cdot 4=4.48$. According to Eq. (6), it is obtained that $C_{3}=\frac{E_{A}}{N}=\frac{4.48}{6}=0.75$. Finally, by applying Eq. (2), the structural complexity is $C=C_{1}+C_{2} \cdot C_{3}=2.25$ min.

The defect prediction model shown in Eq. (1), depending solely on physical design information, is beneficial, especially in the early design stages, when real production data or the physical mockup of the product is not available. This model has been recently applied by the authors in the assembly of a low-volume production of wrapping machines, showing that the relationship between complexity and DPU follows a power-law relationship, as follows $[9,24]$ :

$D P U_{i}=a \cdot\left(C_{i}\right)^{b}=a \cdot\left(C_{1, i}+C_{2, i} \cdot C_{3, i}\right)^{b}$

where $a$ and $b$ are two regression coefficients estimated by nonlinear regression. For the assembly of wrapping machines, the coefficients obtained are $a=3.05 \cdot 10^{-3}$ and $b=1.58$, as will be described in "Sect. 4."

\section{DPU-chart}

Considering the framework described in "Sect. 2," the approach proposed in this study aims to statistically control the process by designing a control chart based on a defect prediction model. In detail, the proposed control chart is designed to monitor $D P U_{i}$ values, i.e., DPU occurring in each $i$-th workstation of the process $(i=1, \ldots, m$, see Fig. 1) in order to detect out of control situations. Accordingly, this chart can be categorized as a control chart for defects per unit (u-chart). Given $x_{i}$ total defects in a sample of $n_{i}$ inspected units in a certain $i$-th workstation, the average number of defects per inspection unit, $D P U_{i}$, can be defined as:

$D P U_{i}=\frac{x_{i}}{n_{i}}$

where $x_{i}$ is the average number of defects (Poisson distributed random variable [5]).

In the proposed DPU-chart, the in-control mean value $D P U_{i}$ is set by a suitable defect prediction model. In the case of electromechanical products, the power-law relationship shown in Eq. (7) can be adopted to this aim. Therefore, for each $i$-th workstation of the process $(i=1, \ldots, m)$, the parameters of the control chart for the average number of defects per unit $\left(D P U_{i}\right)$ may be derived as follows:

$\mathrm{UCL}_{D P U_{i}}=D P U_{i}+3 \cdot \sqrt{\frac{D P U_{i}}{n_{i}}}$

$\mathrm{CL}_{D P U_{i}}=D P U_{i}$

$\mathrm{LCL}_{D P U_{i}}=D P U_{i}-3 \cdot \sqrt{\frac{D P U_{i}}{n_{i}}}$

where $D P U_{i}$, i.e., the in-control mean value of the DPUchart, is modeled by the power-law relationship of Eq. (7).

An example of representation of the control chart for $D P U_{i}$ is provided in Fig. 3.

In "Sect. 4," the proposed methodology is applied to a real-life case study of a company specialized in the design and manufacture of wrapping machines. The case study will 


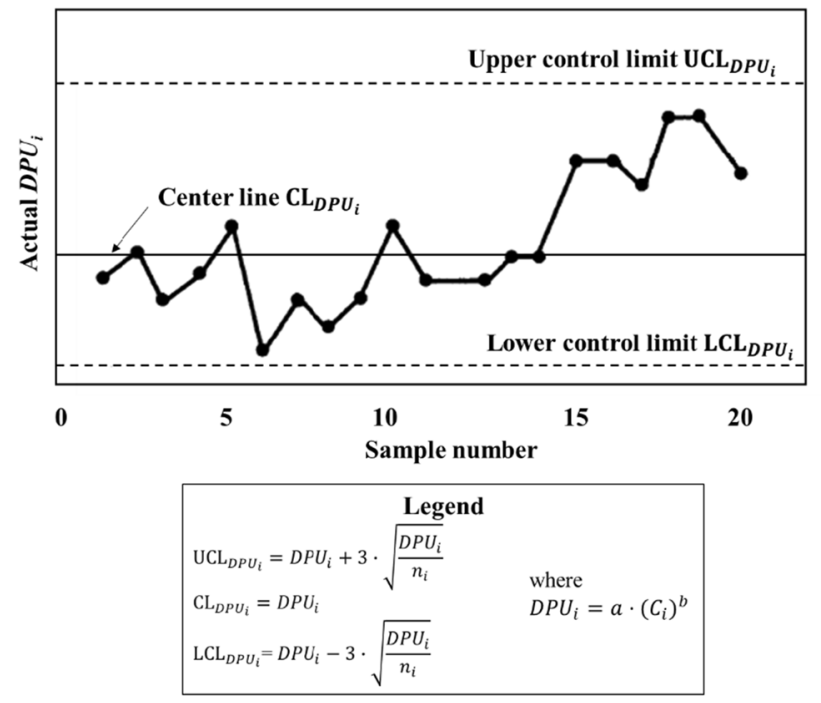

Fig. 3 Example of representation of the DPU-chart

exemplify the application of the approach and will highlight its practical relevance.

\section{Practical case study}

The methodology proposed in "Sect. 3" is applied to the lowvolume production of rotating ring wrapping machines for the packaging of palletized loads, produced by an Italian company (Tosa Group S.p.A.). Typically, each year, about 50 machines are assembled and each of them is highly customized. This study focuses in particular on the assembly of a single part of the rotating ring wrapping machine, i.e., the pre-stretch device, illustrated in Fig. 4. The main reason is that, although each machine differs from the others in some details, this device is common to all assembled machines [20]. The three functions performed by a pre-stretch device are as follows: (i) pulling/ unwinding, (ii) pre-stretch and positioning of the plastic film, and (iii) performing the necessary number of windings.

The assembly process of the pre-stretch device can be subdivided into $m=29$ workstations, listed in Table 2. In this case study, a workstation is meant as an assembly step in which elementary operations are performed, whose output is a sub-assembly, i.e., the workstation-output. As shown in Table 2, in the first 9 workstations, the assembly is performed on the bench by the operator, while in the last 20 workstations the subassemblies are assembled on the frame plate. Each workstation is composed of elementary operations that have definite start and end points and are repeatable regularly throughout the working day [29]. The number of elementary operations in each workstation is also shown in Table 2. The latter, moreover, reports the nominal values of DPU occurring under stationary process conditions in each workstation (nominal $D P U_{i}$ ) that were obtained by drawing on the company historical data [20,23]. These data were considered the reference values of the average defectiveness rate of the assembly process in optimal working conditions and were used to develop a defect prediction model. In detail, according to the model described in "Sect. 2," the structural complexity related to each $i$-th workstation, $C_{i}$, is calculated from the complexities $C_{1, i}, C_{2, i}$, and $C_{3, i}$, listed in Table 2, by applying Eq. (2). To better clarify this step, we propose the calculation of the complexity coefficients for the workstation no. 14 (one of the simplest workstation), related to the transmission system of motor no. 1 assembly. In such a workstation, two components are assembled: the driven wheel and the drive belt. The standard handling time of the two parts is $0.14 \mathrm{~min}$ and the time for connecting them is $0.44 \mathrm{~min}$. Accordingly, by implementing Eqs. (3) and (4), respectively, it is obtained $C_{1}=\sum_{p=1}^{2} \gamma_{p}=$

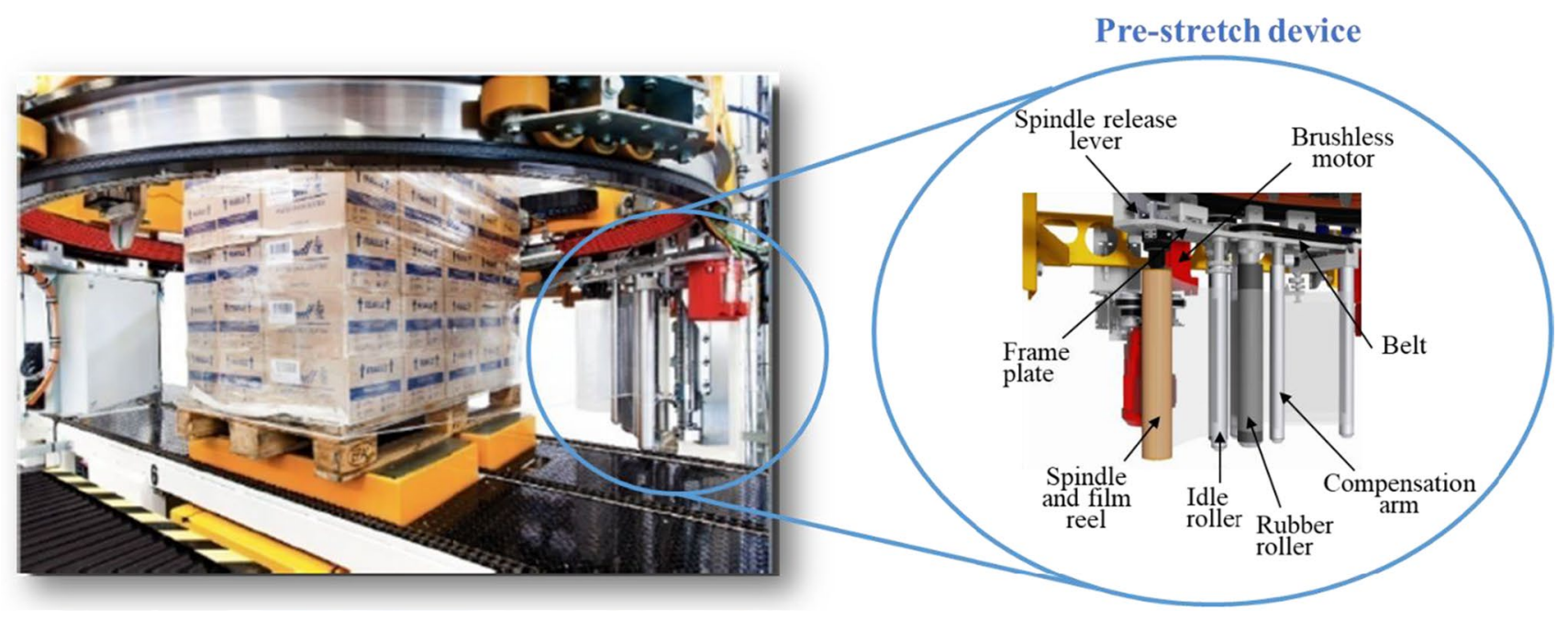

Fig. 4 Rotating ring wrapping machine produced by Tosa Group S.p.A. (Italy) with a focus on the pre-stretch device 
Table 2 Subdivision of the assembly process of the pre-stretch device of wrapping machines into workstations (WS), defect prediction model's variables (see Eq. (7)), nominal $D P U_{i}$ and $D P U_{i}$ predicted by Eq. (10)

\begin{tabular}{|c|c|c|c|c|c|c|c|c|c|}
\hline No. WS & WS description & $\begin{array}{l}\text { No. elementary } \\
\text { operations }\end{array}$ & $C_{1, i}(\min )$ & $C_{2, i}(\min )$ & $N_{i}$ & $C_{3, i}$ & $C_{i}(\min )$ & Nominal $D P U_{i}$ & Predicted $D P U_{i}$ \\
\hline \multicolumn{10}{|c|}{ Bench assembly } \\
\hline 1 & Motor no. 1 bench assembly & 6 & 2.19 & 5.11 & 14 & 0.60 & 5.27 & 0.0364 & 0.0424 \\
\hline 2 & Motor no. 2 bench assembly & 6 & 2.28 & 5.33 & 14 & 0.59 & 5.41 & 0.0364 & 0.0443 \\
\hline 3 & $\begin{array}{l}\text { Support plate of motor no. } 2 \text { bench } \\
\text { assembly }\end{array}$ & 3 & 1.19 & 4.77 & 10 & 0.80 & 5.01 & 0.0182 & 0.0391 \\
\hline 4 & Spindle bench assembly & 3 & 0.78 & 3.14 & 3 & 0.25 & 1.57 & 0.0000 & 0.0062 \\
\hline 5 & Rubber tires bench assembly & 12 & 1.24 & 11.13 & 14 & 0.47 & 6.47 & 0.1091 & 0.0587 \\
\hline 6 & Idle rolls bench assembly & 12 & 1.63 & 6.53 & 12 & 0.62 & 5.68 & 0.0545 & 0.0478 \\
\hline 7 & Rubberized pads bench assembly & 3 & 0.73 & 2.91 & 4 & 0.25 & 1.46 & 0.0000 & 0.0055 \\
\hline 8 & Belt tensioner device bench assembly & 3 & 0.25 & 2.22 & 8 & 1.90 & 4.47 & 0.0364 & 0.0327 \\
\hline 9 & $\begin{array}{l}\text { Driven wheels of transmission system } \\
\text { bench assembly }\end{array}$ & 2 & 0.08 & 0.33 & 4 & 0.25 & 0.16 & 0.0000 & 0.0002 \\
\hline \multicolumn{10}{|c|}{ Assembly on the frame plate } \\
\hline 10 & Pre-stretch frame plate preparation & 3 & 0.99 & 3.97 & 11 & 0.75 & 3.97 & 0.0182 & 0.0271 \\
\hline 11 & $\begin{array}{l}\text { Rubber rollers on pre-stretch frame plate } \\
\text { assembly }\end{array}$ & 4 & 1.07 & 4.27 & 26 & 0.88 & 4.83 & 0.0182 & 0.0369 \\
\hline 12 & $\begin{array}{l}\text { Idle rollers on pre-stretch frame plate } \\
\text { assembly }\end{array}$ & 6 & 1.19 & 4.77 & 39 & 0.83 & 5.15 & 0.0182 & 0.0409 \\
\hline 13 & Motor no. 1 on frame plate assembly & 1 & 0.74 & 2.96 & 5 & 0.25 & 1.48 & 0.0000 & 0.0057 \\
\hline 14 & $\begin{array}{l}\text { Transmission system of motor no. } 1 \\
\text { assembly }\end{array}$ & 2 & 0.14 & 0.44 & 2 & 1.00 & 0.58 & 0.0000 & 0.0013 \\
\hline 15 & Motor no. 2 on frame plate assembly & 4 & 1.73 & 6.90 & 16 & 0.48 & 5.01 & 0.0182 & 0.0391 \\
\hline 16 & $\begin{array}{l}\text { Transmission system of motor no. } 2 \\
\text { assembly }\end{array}$ & 2 & 0.09 & 0.80 & 2 & 3.14 & 2.60 & 0.0364 & 0.0139 \\
\hline 17 & $\begin{array}{l}\text { Motor no. } 1 \text { bracket on pre-stretch frame } \\
\text { plate assembly }\end{array}$ & 1 & 0.20 & 0.78 & 3 & 0.25 & 0.39 & 0.0000 & 0.0007 \\
\hline 18 & $\begin{array}{l}\text { Belt tensioner on pre-stretch frame plate } \\
\text { assembly }\end{array}$ & 2 & 0.18 & 1.64 & 5 & 1.97 & 3.41 & 0.0364 & 0.0213 \\
\hline 19 & $\begin{array}{l}\text { Transmission system of motor no. } 1 \\
\text { calibration }\end{array}$ & 2 & 1.74 & 4.05 & 12 & 0.69 & 4.55 & 0.0364 & 0.0336 \\
\hline 20 & $\begin{array}{l}\text { Transmission system of motor no. } 2 \\
\text { calibration }\end{array}$ & 2 & 1.90 & 4.43 & 12 & 0.66 & 4.81 & 0.0364 & 0.0366 \\
\hline 21 & $\begin{array}{l}\text { Spindle preparation for assembly on pre- } \\
\text { stretch frame plate }\end{array}$ & 2 & 0.45 & 1.79 & 15 & 0.25 & 0.90 & 0.0000 & 0.0026 \\
\hline 22 & $\begin{array}{l}\text { Spindle group on pre-stretch frame plate } \\
\text { assembly }\end{array}$ & 6 & 1.36 & 12.23 & 34 & 0.44 & 6.730 & 0.0364 & 0.0625 \\
\hline 23 & $\begin{array}{l}\text { Rubber pads on pre-stretch frame plate } \\
\text { assembly }\end{array}$ & 2 & 0.47 & 1.89 & 5 & 0.25 & 0.94 & 0.0000 & 0.0028 \\
\hline 24 & Motor assembly no. 1 final steps & 1 & 0.12 & 1.04 & 3 & 2.88 & 3.09 & 0.0545 & 0.0182 \\
\hline 25 & Motor assembly no. 2 final steps & 1 & 0.12 & 1.08 & 3 & 2.77 & 3.11 & 0.0545 & 0.0184 \\
\hline 26 & Spindle release lever bench assembly & 1 & 0.24 & 0.95 & 6 & 0.25 & 0.48 & 0.0000 & 0.0009 \\
\hline 27 & $\begin{array}{l}\text { Spindle release lever on pre-stretch frame } \\
\text { plate assembly }\end{array}$ & 3 & 0.80 & 7.20 & 6 & 0.25 & 2.60 & 0.0000 & 0.0139 \\
\hline 28 & Compensation arm bench assembly & 9 & 1.26 & 11.32 & 20 & 0.60 & 8.05 & 0.0909 & 0.0830 \\
\hline 29 & $\begin{array}{l}\text { Compensation arm on pre-stretch frame } \\
\text { plate assembly }\end{array}$ & 3 & 0.56 & 5.00 & 4 & 0.25 & 1.81 & 0.0000 & 0.0078 \\
\hline
\end{tabular}

$0.14 \mathrm{~min}$ and $C_{2}=\sum_{p=1}^{1} \sum_{r=p+1}^{2} \varphi_{p r} \cdot A_{p r}=0.44 \mathrm{~min}$, as reported Table 2 . The adjacency matrix of the two components is $\boldsymbol{A}=\left(\begin{array}{ll}0 & 1 \\ 1 & 0\end{array}\right)$. The two different eigenvalues of $\boldsymbol{A}$ are
1 and -1 . Thus, the graph energy $E_{A}$ is computed as the sum of its singular values that are the absolute eigenvalues of $\boldsymbol{A}$ in case of symmetric matrix: $E_{A}=1+1=2$. According to 
Eq. (6), $C_{3}=\frac{E_{A}}{N}=\frac{2}{2}=1$. Finally, by Eq. (2), the structural complexity of this workstation is $C=C_{1}+C_{2} \cdot C_{3}=$ $0.58 \mathrm{~min}$.

Different models were tested and compared to relate $D P U_{i}$ versus $C_{i}$. The adequacy of such models was assessed based on the analysis of regression residuals and of the $S$ value as a measure of goodness-of-fit [30, 31]. A powerlaw curve was found to be the best model to define such a relationship, as discussed in "Sect. 2." Accordingly, the defect prediction model, obtained according to Eq. (7), is the following $[9,24]$ :

$D P U_{i}=3.05 \cdot 10^{-3} \cdot\left(C_{i}\right)^{1.58}$

Table 2 finally reports the $D P U_{i}$ values predicted by Eq. (10).

The average number of defects per unit in each workstation, $D P U_{i}$, is tracked by inspectors on a bimonthly basis. In detail, every 2 months, 9 devices are assembled by the company in each $i$-th workstation and, accordingly, the sample size is $n_{i}=9$. Each $i$-th workstation-output $(i=1, \ldots, 29)$ is examined by inspectors that record the total number of defects occurring during each bimester. Inspectors perform various quality control activities to detect these defects, which may require specific equipment depending on the workstation-output [9]. The adopted inspection controls are listed in Table 3. Then, for all the workstations, the recorded defects are divided by the number of devices produced in each bimester to obtain the average defects per unit. The most recent $D P U_{i}$ values related to the last 12 bimesters (2 years) are reported in Table 4.

The DPU-chart developed in "Sect. 3" can be used to monitor the process. Adopting the DPU prediction model greatly speeds up the construction of the control chart. Indeed, since the preliminary collection of experimental data (phase I) is not necessary for the new approach, a time saving of several months is achieved (considering that data for 50 machines are obtained in one production year). In detail, according to Eqs. (9a), (9b), and (9c), the parameters of each DPU-chart are derived and are reported in Table 4. Since $\mathrm{LCL}_{D P U_{i}}<0$ for each $i$-th workstation, it is set $\mathrm{LCL}_{D P U_{i}}=0$ for the chart.

A DPU-chart is obtained for all the workstations. As an example, the DPU-chart for workstation no. 1 is provided in Fig. 5. As can be seen, the workstation 1 appears in statistical control.

When some points fall outside of the control limits and/or points behave in a systematic or nonrandom manner, there is evidence that the process is out of control, and investigation and corrective actions are required to find and eliminate the assignable causes responsible for this behavior. As an example, from the data in Table 4, a lack of statistical control is exhibited for workstations no. 10 and 26. In detail, the chart for workstation 10 highlights an increasing trend of the $D P U$ values from the bimester no. 8, and two observation (i.e., corresponding to bimester no. 10 and 12) are signaled as out of control points, as shown in Fig. 6. On the other hand, for workstation no. 26, five out of control $D P U$ values are detected by the chart, corresponding to bimester no. 4, 8, 9, 10, and 11 (see Fig. 7). In order to investigate the causes leading to the anomalous defectiveness found in the two workstations, specific and accurate checks were carried out. Regarding workstation 10, the critical assembly operation was the finishing of the frame plate holes, performed by the operator with a manual grinding machine. The inadequate training of the operator was identified as the variation cause. On the other side, the root cause of the workstation 26 behavior was a batch of an out-of-tolerance mechanical component purchased from an external supplier used for assembling the spindle release lever.

\section{Application guidelines}

The proposed DPU-chart could be very useful when a defect prediction model is available. Otherwise, some evaluations ought to be made. In detail, the following guidelines should be considered before designing a DPU-chart:

- Case (i): a model for predicting DPU is available.

If a suitable model for predicting DPU is available, adopting a DPU-chart can be considered more convenient than a traditional $u$-chart, avoiding the implementation of phase I and directly deriving control limits from prior product knowledge. The prediction model is certainly closely linked to the specific manufacturing field. In the case of assembly processes, the prediction model framework described in "Section 2" can be adopted, and Eq. (7) can be considered a suitable equation to model DPUs in various applications. However, the regression coefficients $a$ and $b$ (see "Section 2") may vary according to the specific industrial field. As aforementioned, in the case of wrapping machines, these coefficients are known from a previous study [24]. This model for wrapping machines can, to a certain extent, be preliminary extended to other similar applications in assembly production, particularly electromechanical products.

Otherwise, in sectors other than the electromechanical, alternative prediction models may be adopted, with settings based on literature data and/or previous experience (see, e.g., defect/fault prediction models for software applications [32, 33]).

- Case (ii): a predictive model is not available.

In such a case, the interest in the proposed DPU-charts may be less evident, having to replace phase I with the 
Table 3 Type and description of the controls performed in the workstations of the pre-stretch device to detect defects [9]

\begin{tabular}{|c|c|c|}
\hline No. WS & Control type & Control description \\
\hline 1 & Visual and manual & $\begin{array}{l}\text { Cleaning of motor shaft } 1 \text {, alignment of groups pulley-motor shaft } 1 \text { and clamping ring-motor shaft } \\
1\end{array}$ \\
\hline 2 & Visual, manual, and dimensional & $\begin{array}{l}\text { Cleaning of motor shaft } 2 \text {, correct dimensions of the groups shrink disk-crankshaft } 2 \text { and pulley- } \\
\text { crankshaft } 2 \text { by using caliber and bench vice }\end{array}$ \\
\hline 3 & Visual and manual & Surface cleaning of motor support plate 2 and correct assembly of the upper and lower plate \\
\hline 4 & Visual, manual, and mechanical & Presence of all the components for the spindle subassembly and spindle spring operation \\
\hline 5 & Visual, manual, and mechanical & Cleaning of the wheeled roller shaft and correct rotation of the wheeled roller assembly \\
\hline 6 & Visual, manual, and mechanical & Cleaning of idle rolls shaft and correct rotation of idle rollers assembly \\
\hline 7 & Visual and geometric & $\begin{array}{l}\text { Correct positioning of the rubber pad assembly } 1 \text { and } 2 \text { and hexagonal support of the rubber pad } \\
\text { assembly } 1 \text { and } 2\end{array}$ \\
\hline 8 & Visual and mechanical & $\begin{array}{l}\text { Alignment of the belt tensioning device group and correct rotation of the belt tensioning device } \\
\text { roller }\end{array}$ \\
\hline 9 & Visual and mechanical & $\begin{array}{l}\text { Penetration of the protective on the surface of the driven wheels and correct positioning of the } \\
\text { clamping rings in the transmission-driven wheels }\end{array}$ \\
\hline 10 & Visual & Esthetic appearance of the surface plate of the pre-stretch frame \\
\hline 11 & Mechanical and geometric & Correct rotation of the rubber rolls and alignment of the rubber rollers on the pre-stretch frame plate \\
\hline 12 & Mechanical and geometric & Correct idle roller rotation and alignment of the idle rollers on the pre-stretch frame plate \\
\hline 13 & Mechanical & Correct tightening of the motor bolts 1 on the frame plate \\
\hline 14 & Visual & Correct positioning of the components \\
\hline 15 & Visual and mechanical & Correct tightening of motor bolts 2 on the frame plate \\
\hline 16 & Visual & Correct positioning of components \\
\hline 17 & Visual & Correct positioning of the motor casing 1 \\
\hline 18 & Mechanical and geometric & Correct alignment of the belt tensioner assembly and rotation of the belt tensioning device roller \\
\hline 19 & Mechanical and geometric & Movement of the motor drive belt 1 \\
\hline 20 & Mechanical and geometric & Movement of the motor drive belt 2 \\
\hline 21 & Visual and mechanical & $\begin{array}{l}\text { Check the number of screws removed from the component and correct operation of the internal } \\
\text { spindle spring }\end{array}$ \\
\hline 22 & Mechanical and geometric & $\begin{array}{l}\text { Correct spindle rotation on the pre-stretch frame plate and alignment of the spindle assembly on the } \\
\text { pre-stretch frame plate }\end{array}$ \\
\hline 23 & Geometric & Correct alignment of the pads on the pre-stretch frame plate \\
\hline 24 & Manual and mechanical & $\begin{array}{l}\text { Correct operation of the motor } 1 \text {, final check of the motor } 1 \text { drive belt tension and final alignment } \\
\text { check of the motor } 1 \text { transmission assembly }\end{array}$ \\
\hline 25 & Manual and mechanical & $\begin{array}{l}\text { Correct operation of the motor } 2 \text {, final check of the motor } 2 \text { drive belt tension and final alignment } \\
\text { check of the motor } 2 \text { transmission assembly }\end{array}$ \\
\hline 26 & Visual and mechanical & Alignment and correct movement of spindle release lever assembly \\
\hline 27 & Mechanical and geometric & Correct movement and alignment of the spindle release lever on the pre-stretch frame plate \\
\hline 28 & $\begin{array}{l}\text { Visual, geometric, mechanical, } \\
\text { and dimensional }\end{array}$ & $\begin{array}{l}\text { Correct rotation of the compensation arm roller and alignment of the cam system by using caliber, } \\
\text { metallic ruler, and gauge blocks }\end{array}$ \\
\hline 29 & Visual and mechanical & $\begin{array}{l}\text { Correct movement of the compensation arm assembly on the pre-stretch frame plate and correct } \\
\text { rotation of the compensation arm roller }\end{array}$ \\
\hline
\end{tabular}

construction of the defect model. As a consequence, it is necessary to evaluate case by case if it is more convenient to implement phase I or to build a new defect prediction model.

Referring to the case (i), to empirically validate the suitability of the prediction model developed for wrapping machines - see Eq. (10) — to other electromechanical products, a comparison is performed with a similar application related to the assembly of hardness testing machines.
The new proposed case study concerns the assembly of the AFFRI® LD 3000 AF machine and, in particular, its machine head. As described in a previous paper [8], the assembly of machine head of hardness testing machines may be subdivided into 18 workstations. For each workstation, the $D P U_{i}$ are reported in Table 5. To build the prediction model, the structural complexity $C_{i}$ is used as predictor, according to the Alkan [25] and Sinha [26] model (see "Sect. 2"). The obtained values are listed in Table 5. By applying Eq. (7), the regression model coefficients, denoted 
Table $4 D P U_{i}$ values related to each $i$-th workstation of the pre-stretch device tracked on a bimonthly basis. Out of control observations are written in bold type

\begin{tabular}{|c|c|c|c|c|c|c|c|c|c|c|c|c|c|c|c|}
\hline \multirow[t]{2}{*}{ WS } & \multicolumn{12}{|c|}{ Sample number (bimester) } & \multirow[t]{2}{*}{$\mathrm{LCL}_{D P U_{i}}$} & \multirow[t]{2}{*}{$\mathrm{CL}_{D P U_{i}}$} & \multirow[t]{2}{*}{$\mathrm{UCL}_{D P U}$} \\
\hline & 1 & 2 & 3 & 4 & 5 & 6 & 7 & 8 & 9 & 10 & 11 & 12 & & & \\
\hline 1 & 0.0000 & 0.2222 & 0.1111 & 0.0000 & 0.0000 & 0.1111 & 0.1111 & 0.2222 & 0.0000 & 0.1111 & 0.1111 & 0.0000 & 0.0000 & 0.0424 & 0.2482 \\
\hline 2 & 0.0000 & 0.1111 & 0.0000 & 0.1111 & 0.0000 & 0.0000 & 0.0000 & 0.0000 & 0.1111 & 0.0000 & 0.0000 & 0.1111 & 0.0000 & 0.0443 & 0.2546 \\
\hline 3 & 0.0000 & 0.0000 & 0.0000 & 0.0000 & 0.0000 & 0.0000 & 0.0000 & 0.0000 & 0.0000 & 0.0000 & 0.0000 & 0.0000 & 0.0000 & 0.0391 & 0.2368 \\
\hline 4 & 0.0000 & 0.0000 & 0.0000 & 0.0000 & 0.0000 & 0.0000 & 0.0000 & 0.0000 & 0.0000 & 0.0000 & 0.0000 & 0.0000 & 0.0000 & 0.0062 & 0.0851 \\
\hline 5 & 0.0000 & 0.2222 & 0.1111 & 0.0000 & 0.1111 & 0.2222 & 0.1111 & 0.2222 & 0.0000 & 0.1111 & 0.1111 & 0.1111 & 0.0000 & 0.0587 & 0.3009 \\
\hline 6 & 0.1111 & 0.1111 & 0.0000 & 0.1111 & 0.0000 & 0.0000 & 0.1111 & 0.1111 & 0.0000 & 0.1111 & 0.2222 & 0.0000 & 0.0000 & 0.0478 & 0.2664 \\
\hline 7 & 0.0000 & 0.0000 & 0.0000 & 0.0000 & 0.0000 & 0.0000 & 0.0000 & 0.0000 & 0.0000 & 0.0000 & 0.0000 & 0.0000 & 0.0000 & 0.0055 & 0.0799 \\
\hline 8 & 0.0000 & 0.1111 & 0.0000 & 0.0000 & 0.1111 & 0.0000 & 0.0000 & 0.0000 & 0.1111 & 0.0000 & 0.0000 & 0.1111 & 0.0000 & 0.0327 & 0.2135 \\
\hline 9 & 0.0000 & 0.0000 & 0.0000 & 0.0000 & 0.0000 & 0.0000 & 0.0000 & 0.0000 & 0.0000 & 0.0000 & 0.0000 & 0.0000 & 0.0000 & 0.0002 & 0.0134 \\
\hline 10 & 0.0000 & 0.0000 & 0.1111 & 0.1111 & 0.0000 & 0.0000 & 0.1111 & 0.0000 & 0.1111 & 0.2222 & 0.1111 & 0.4444 & 0.0000 & 0.0271 & 0.1916 \\
\hline 11 & 0.0000 & 0.0000 & 0.0000 & 0.1111 & 0.0000 & 0.1111 & 0.0000 & 0.2222 & 0.0000 & 0.0000 & 0.0000 & 0.0000 & 0.0000 & 0.0369 & 0.2290 \\
\hline 12 & 0.0000 & 0.0000 & 0.0000 & 0.0000 & 0.0000 & 0.0000 & 0.0000 & 0.0000 & 0.0000 & 0.0000 & 0.0000 & 0.0000 & 0.0000 & 0.0409 & 0.2431 \\
\hline 13 & 0.0000 & 0.0000 & 0.0000 & 0.0000 & 0.0000 & 0.0000 & 0.0000 & 0.0000 & 0.0000 & 0.0000 & 0.0000 & 0.0000 & 0.0000 & 0.0057 & 0.0810 \\
\hline 14 & 0.0000 & 0.0000 & 0.0000 & 0.0000 & 0.0000 & 0.0000 & 0.0000 & 0.0000 & 0.0000 & 0.0000 & 0.0000 & 0.0000 & 0.0000 & 0.0013 & 0.0373 \\
\hline 15 & 0.0000 & 0.0000 & 0.1111 & 0.0000 & 0.0000 & 0.0000 & 0.0000 & 0.0000 & 0.2222 & 0.0000 & 0.0000 & 0.1111 & 0.0000 & 0.0391 & 0.2370 \\
\hline 16 & 0.0000 & 0.0000 & 0.0000 & 0.0000 & 0.0000 & 0.0000 & 0.0000 & 0.1111 & 0.0000 & 0.0000 & 0.0000 & 0.0000 & 0.0000 & 0.0139 & 0.1317 \\
\hline 17 & 0.0000 & 0.0000 & 0.0000 & 0.0000 & 0.0000 & 0.0000 & 0.0000 & 0.0000 & 0.0000 & 0.0000 & 0.0000 & 0.0000 & 0.0000 & 0.0007 & 0.0270 \\
\hline 18 & 0.0000 & 0.0000 & 0.1111 & 0.1111 & 0.0000 & 0.0000 & 0.1111 & 0.0000 & 0.0000 & 0.0000 & 0.1111 & 0.0000 & 0.0000 & 0.0213 & 0.1671 \\
\hline 19 & 0.0000 & 0.1111 & 0.0000 & 0.0000 & 0.1111 & 0.0000 & 0.0000 & 0.1111 & 0.0000 & 0.0000 & 0.1111 & 0.0000 & 0.0000 & 0.0336 & 0.2169 \\
\hline 20 & 0.1111 & 0.0000 & 0.0000 & 0.0000 & 0.0000 & 0.1111 & 0.0000 & 0.0000 & 0.1111 & 0.0000 & 0.0000 & 0.1111 & 0.0000 & 0.0366 & 0.2281 \\
\hline 21 & 0.0000 & 0.0000 & 0.0000 & 0.0000 & 0.0000 & 0.0000 & 0.0000 & 0.0000 & 0.0000 & 0.0000 & 0.0000 & 0.0000 & 0.0000 & 0.0026 & 0.0532 \\
\hline 22 & 0.0000 & 0.0000 & 0.0000 & 0.0000 & 0.0000 & 0.2222 & 0.0000 & 0.1111 & 0.1111 & 0.0000 & 0.0000 & 0.0000 & 0.0000 & 0.0625 & 0.3124 \\
\hline 23 & 0.0000 & 0.0000 & 0.0000 & 0.0000 & 0.0000 & 0.0000 & 0.0000 & 0.0000 & 0.0000 & 0.0000 & 0.0000 & 0.0000 & 0.0000 & 0.0028 & 0.0556 \\
\hline 24 & 0.0000 & 0.1111 & 0.0000 & 0.0000 & 0.0000 & 0.0000 & 0.1111 & 0.0000 & 0.0000 & 0.1111 & 0.1111 & 0.0000 & 0.0000 & 0.0182 & 0.1533 \\
\hline 25 & 0.0000 & 0.1111 & 0.1111 & 0.0000 & 0.1111 & 0.0000 & 0.0000 & 0.0000 & 0.1111 & 0.0000 & 0.0000 & 0.0000 & 0.0000 & 0.0184 & 0.1541 \\
\hline 26 & 0.0000 & 0.0000 & 0.0000 & 0.1111 & 0.0000 & 0.0000 & 0.0000 & 0.1111 & 0.2222 & 0.1111 & 0.1111 & 0.0000 & 0.0000 & 0.0009 & 0.0316 \\
\hline 27 & 0.0000 & 0.0000 & 0.0000 & 0.0000 & 0.0000 & 0.0000 & 0.0000 & 0.0000 & 0.0000 & 0.0000 & 0.0000 & 0.0000 & 0.0000 & 0.0139 & 0.1316 \\
\hline 28 & 0.0000 & 0.0000 & 0.0000 & 0.0000 & 0.0000 & 0.3333 & 0.3333 & 0.3333 & 0.1111 & 0.2222 & 0.0000 & 0.0000 & 0.0000 & 0.0830 & 0.3710 \\
\hline 29 & 0.0000 & 0.0000 & 0.0000 & 0.0000 & 0.0000 & 0.0000 & 0.0000 & 0.0000 & 0.0000 & 0.0000 & 0.0000 & 0.0000 & 0.0000 & 0.0078 & 0.0960 \\
\hline
\end{tabular}

Fig. 5 DPU-chart for the $i$-th workstation $(i=1)$
DPU-control chart for workstation no. 1

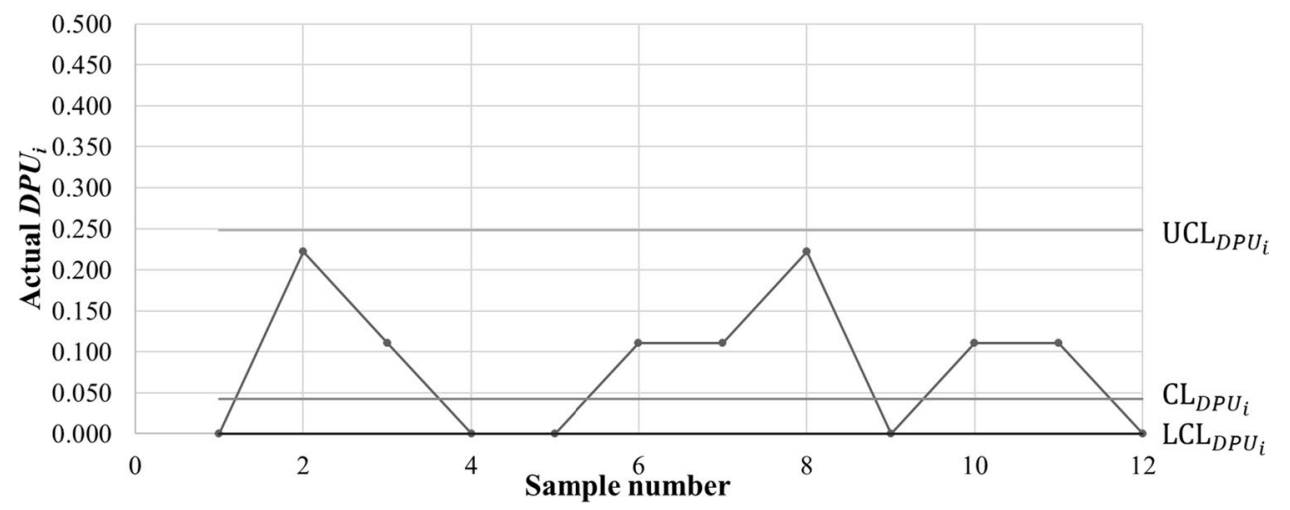


Fig. 6 DPU-chart for the $i$-th workstation $(i=10)$

Fig. 7 DPU-chart for the $i$-th workstation $(i=26)$

Table 5 Structural complexity and defects per unit relevant to the workstations of the machine head of hardness testing machines
DPU-control chart for workstation no. 10

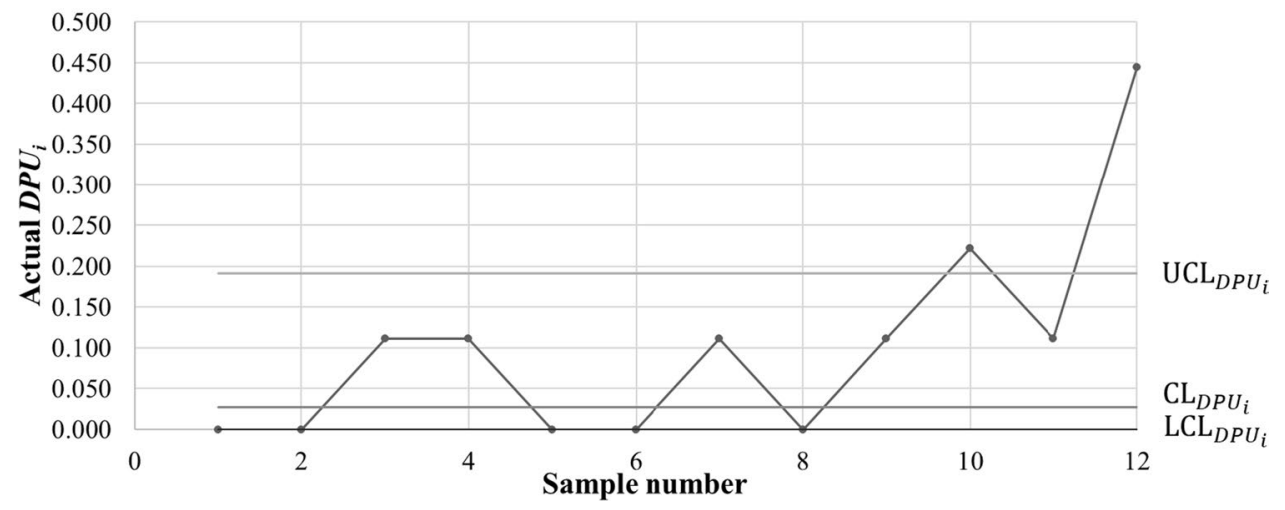

DPU-control chart for workstation no. 26

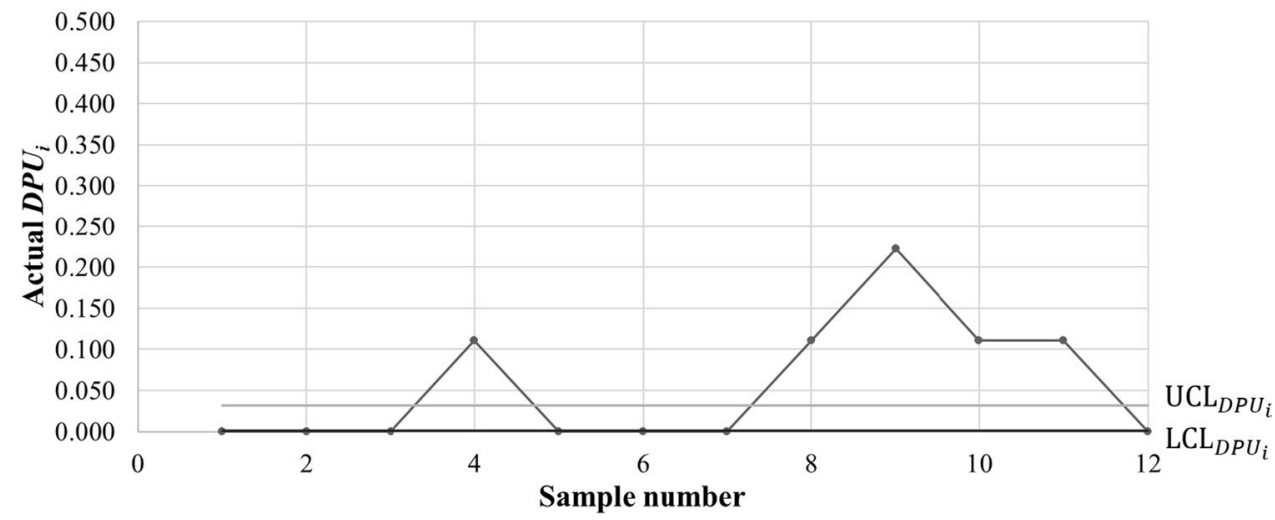

\begin{tabular}{lll}
\hline WS & $C_{i}(\min )$ & $D P U_{i}$ \\
\hline 1 & 1.34 & 0.0055 \\
2 & 1.06 & 0.0050 \\
3 & 0.58 & 0.0012 \\
4 & 0.84 & 0.0019 \\
5 & 0.33 & 0.0005 \\
6 & 0.60 & 0.0026 \\
7 & 1.29 & 0.0049 \\
8 & 0.54 & 0.0015 \\
9 & 0.38 & 0.0004 \\
10 & 1.36 & 0.0044 \\
11 & 0.93 & 0.0026 \\
12 & 0.12 & 0.0007 \\
13 & 0.67 & 0.0015 \\
14 & 0.17 & 0.0005 \\
15 & 0.94 & 0.0025 \\
16 & 0.57 & 0.0005 \\
17 & 0.16 & 0.0009 \\
18 & 1.02 & 0.0033 \\
\hline
\end{tabular}

respectively $a^{\prime}$ and $b^{\prime}$, are: $a^{\prime}=3.25 \cdot 10^{-3}$ and $b^{\prime}=1.52$. Figure 8 compares the $95 \%$ confidence intervals of the regression coefficients of the two empirical models (i.e., that for the wrapping machines and that for hardness testing machines). The confidence intervals of both the regression coefficients are comparable as they overlap each other, thus indicating that the model developed for wrapping machines - Eq. (10) - may also be usable, as a first approximation, for different applications pertaining to the electromechanical field.

\section{Conclusions}

Identifying suitable statistical process control (SPC) tools to control and monitor manufacturing processes is a key aspect of many industrial companies. In the modern industry, production volume continues to shrink due to the increasing customization and complexity of products. As a result, more 


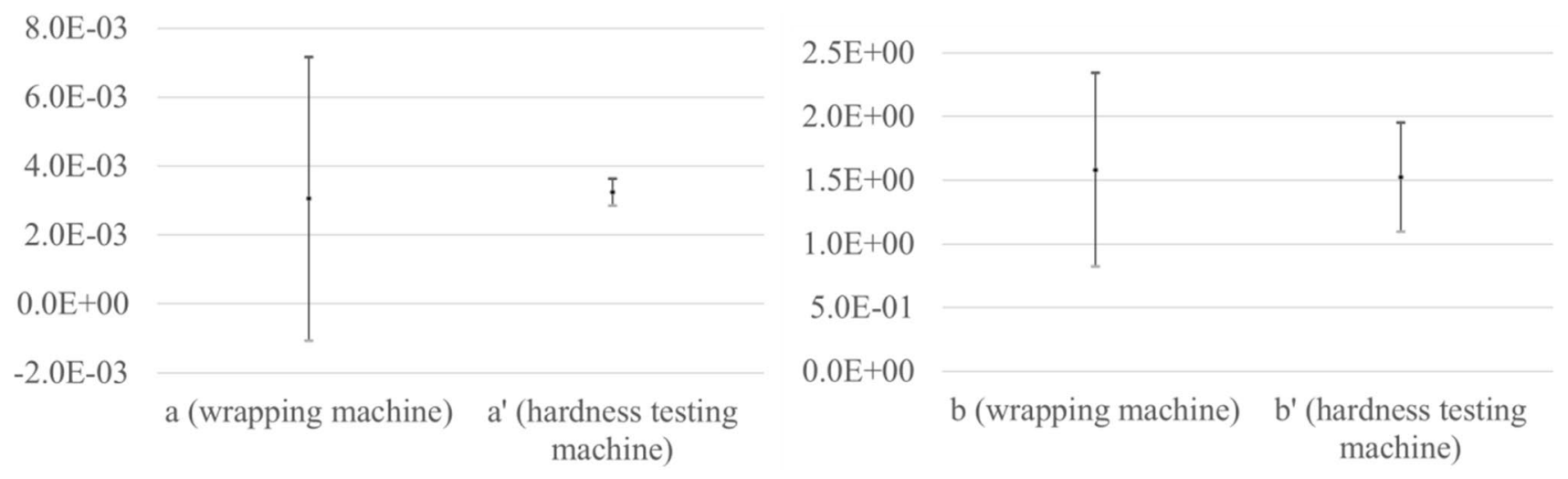

Fig. 8 Comparison of 95\% confidence intervals of regression coefficient estimates of Eq. (7) obtained for wrapping machines and hardness testing machines [8]

and more small batches are produced (the so-called lowvolume production). In this context, collecting experimental data to implement traditional SPC tools may be timeconsuming, costly, and challenging. This paper proposes a novel DPU-chart based on the use of defect prediction models for assembled products.

In contrast to traditional monitoring charts, DPU-charts do not require preliminary experimental data in the phase of construction of the chart (phase I). Several prediction models have been developed in the scientific literature to predict defects per unit (DPU) occurring in the assembly workstations. In this research, the model developed by the authors in a previous study [9] in the electromechanical field is used to predict DPU occurring in each workstation from product structural complexity.

The proposed DPU-chart may be particularly beneficial when a defect prediction model is available, as it allows to avoid the construction of a conventional SPC chart (phase I) and to derive control limits directly from product assembly structure knowledge. In particular, through an empirical comparison with hardness testing machines assembly, it was obtained that the model developed for wrapping machines can also be preliminary suitable for other similar applications in the electromechanical field. Conversely, if a predictive model is not available, it is necessary to evaluate, on a case-by-case basis, whether it is more beneficial to adopt a conventional SPC chart or to build a new specific defect prediction model.

The novel approach to set up the DPU-chart can be of great help to improve process monitoring and control especially in a context of low-volume manufacturing, for which implementing phase I would typically take very long time to get enough data. As a result, the construction of the chart can be significantly accelerated, thus avoiding delaying the next monitoring phase. The relevance of this novel paradigm is supported by the findings obtained in a real production of wrapping machines, showing how the monitoring process can be successfully improved. Further research will be addressed to explore the use of artificial intelligence (AI) techniques to develop reliable defect prediction models that can be used as an alternative to the one proposed in this study.

Acknowledgements The authors gratefully acknowledge the company Tosa Group S.p.A. (Italy) for the collaboration in this project.

Author contribution The authors have provided an equal contribution to the drafting of the paper.

Funding Open access funding provided by Politecnico di Torino within the CRUI-CARE Agreement.. This work has been partially supported by the "Italian Ministry of Education, University and Research," Award "TESUN-83486178370409 finanziamento dipartimenti di eccellenza CAP. 1694 TIT. 232 ART. 6."

Availability of data and materials Not applicable.

\section{Declarations}

Ethics approval The authors respect the ethical guidelines of the journal.

Consent to participate Not applicable.

Consent for publication Not applicable.

Competing interests The authors declare no competing interests.

Open Access This article is licensed under a Creative Commons Attribution 4.0 International License, which permits use, sharing, adaptation, distribution and reproduction in any medium or format, as long as you give appropriate credit to the original author(s) and the source, provide a link to the Creative Commons licence, and indicate if changes were made. The images or other third party material in this article are included in the article's Creative Commons licence, unless indicated otherwise in a credit line to the material. If material is not included in the article's Creative Commons licence and your intended use is not permitted by statutory regulation or exceeds the permitted use, you will 
need to obtain permission directly from the copyright holder. To view a copy of this licence, visit http://creativecommons.org/licenses/by/4.0/.

\section{References}

1. Ali S, Pievatolo A, Göb R (2016) An overview of control charts for high-quality processes. Qual Reliab Eng Int 32:2171-2189

2. Du Nguyen H, Nguyen QT, Tran KP, Ho DP (2019) On the performance of VSI Shewhart control chart for monitoring the coefficient of variation in the presence of measurement errors. Int $\mathrm{J}$ Adv Manuf Technol 104:211-243

3. Hossain MP, Sanusi RA, Omar MH, Riaz M (2019) On designing Maxwell CUSUM control chart: an efficient way to monitor failure rates in boring processes. Int J Adv Manuf Technol 100:1923-1930

4. Nazir HZ, Hussain T, Akhtar N et al (2019) Robust adaptive exponentially weighted moving average control charts with applications of manufacturing processes. Int J Adv Manuf Technol 105:733-748

5. Montgomery DC (2012) Statistical quality control, 7th edn. John Wiley \& Sons, New York

6. Del Castillo E, Grayson JM, Montgomery DC, Runger GC (1996) A review of statistical process control techniques for short run manufacturing systems. Commun Stat Methods 25:2723-2737

7. Koons GF, Luner JJ (1991) SPC in low-volume manufacturing: a case study. J Qual Technol 23:287-295

8. Galetto M, Verna E, Genta G, Franceschini F (2020) Uncertainty evaluation in the prediction of defects and costs for quality inspection planning in low-volume productions. Int J Adv Manuf Technol 108:3793-3805

9. Verna E, Genta G, Galetto M, Franceschini F (2021) Inspection planning by defect prediction models and inspection strategy maps. Prod Eng 15(6):897-915. https://doi.org/10.1007/ 2Fs11740-021-01067-x

10. Hinckley CM (1994) A global conformance quality model. A new strategic tool for minimizing defects caused by variation, error, and complexity. $\mathrm{PhD}$ dissertation, Mechanical Engineering Department, Stanford University

11. Psarommatis F, May G, Dreyfus P-A, Kiritsis D (2020) Zero defect manufacturing: state-of-the-art review, shortcomings and future directions in research. Int J Prod Res 58:1-17

12. Genta G, Galetto M, Franceschini F (2018) Product complexity and design of inspection strategies for assembly manufacturing processes. Int J Prod Res 56:4056-4066

13. Shibata H (2002) Global assembly quality methodology: a new methodology for evaluating assembly complexities in globally distributed manufacturing. PhD dissertation, Mechanical Engineering Department, Stanford University

14. Su Q, Liu L, Whitney DE (2010) A systematic study of the prediction model for operator-induced assembly defects based on assembly complexity factors. IEEE Trans Syst Man Cybern - Part A Syst Humans 40:107-120

15. Antani KR (2014) A Study of the effects of manufacturing complexity on product quality in mixed-model automotive assembly. PhD dissertation, Mechanical Engineering Department, Clemson University

16. Krugh M, Antani K, Mears L, Schulte J (2016) Prediction of defect propensity for the manual assembly of automotive electrical connectors. Procedia Manuf 5:144-157
17. Falck A-C, Örtengren R, Rosenqvist M, Söderberg R (2017) Proactive assessment of basic complexity in manual assembly: development of a tool to predict and control operator-induced quality errors. Int J Prod Res 55:4248-4260

18. Galetto M, Verna E, Genta G (2020) Accurate estimation of prediction models for operator-induced defects in assembly manufacturing processes. Qual Eng 32:595-613

19. Le Y, Qiang S, Liangfa S (2012) A novel method of analyzing quality defects due to human errors in engine assembly line. In: Information management, innovation management and industrial engineering (ICIII), 2012 international conference on information management, innovation management and industrial engineering (ICIII). IEEE, 20-21 October 2012, Sanya, China, pp 154-157

20. Verna E, Genta G, Galetto M, Franceschini F (2021) Defect prediction models to improve assembly processes in low-volume productions. Procedia CIRP 97:148-153

21. Galetto M, Genta G, Maculotti G, Verna E (2020) Defect probability estimation for hardness-optimised parts by selective laser melting. Int J Precis Eng Manuf 21:1739-1753

22. Verna E, Genta G, Galetto M, Franceschini F (2020) Planning offline inspection strategies in low-volume manufacturing processes. Qual Eng 32:705-720

23. Verna E, Genta G, Galetto M, Franceschini F (2020) Defect prediction model for wrapping machines assembly. In: Proceedings of the 4th international conference on quality engineering and management. 21-22 September, University of Minho, Braga, Portugal, pp 115-134. ISSN: 21843481, ISBN: 978-989549110-0

24. Verna E, Genta G, Galetto M, Franceschini F (2020) Defect prediction for assembled products: a novel model based on the structural complexity paradigm. Submitt to J Intell Manuf

25. Alkan B (2019) An experimental investigation on the relationship between perceived assembly complexity and product design complexity. Int J Interact Des Manuf 13:1145-1157

26. Sinha K (2014) Structural complexity and its implications for design of cyber-physical systems. PhD dissertation, Engineering Systems Division, Massachusetts Institute of Technology

27. Nikiforov V (2007) The energy of graphs and matrices. J Math Anal Appl 326:1472-1475

28. Li X, Shi Y, Gutman I (2012) Hyperenergetic and equienergetic graphs. Graph energy. Springer, New York, NY, pp 193-201

29. Aft LS (2000) Work measurement and methods improvement. John Wiley \& Sons, Hoboken, NJ, USA

30. Bates DM, Watts DG (1988) Nonlinear regression analysis and its applications. John Wiley \& Sons Inc, Hoboken, NJ, USA

31. Spiess AN, Neumeyer N (2010) An evaluation of R2 as an inadequate measure for nonlinear models in pharmacological and biochemical research: a Monte Carlo approach. BMC Pharmacol 10:1-11

32. Sharma D, Chandra P (2020) Towards recent developments in the methods, metrics and datasets of software fault prediction. Int $\mathrm{J}$ Comput Syst Eng 6:14-45

33. Jin C (2020) Software defect prediction model based on distance metric learning. Soft Comput 1-15

Publisher's note Springer Nature remains neutral with regard to jurisdictional claims in published maps and institutional affiliations. 